\title{
Adsorption onto Granular Activated Carbon (GAC) as an Emerging Technology for the Recovery of Aroma Compounds in the Fruit Juice Industry
}

\author{
Diban, N., Ruiz, G., Urtiaga, A., Ortiz, I. \\ Department of Chemical Engineering. University of Cantabria \\ Avda. de los Castros s/n. 39005 Santander. Spain
}

\footnotetext{
* Corresponding author. Tel.: +34 942201585; fax: +34 942 201591. e-mail address: ortizi@unican.es
} 


\begin{abstract}
Adsorption/desorption of ethyl 2, 4-decadienoate from the aqueous fruit juice on granular activated carbon (GAC) was investigated as efficient technology in the recovery and concentration of this valuable aroma component, substituting the current rectification column employed in the industrial process. The equilibrium and kinetics of the separation processes were analyzed in a previous work at different temperatures ranging from 283 to $322 \mathrm{~K}$ obtaining the kinetic model and parameters that allowed the description of the process. The obtained information was used to calculate the dimensions of a GAC adsorption bed that could be used to treat $7 \mathrm{~m}^{3} \mathrm{~h}^{-1}$ of fruit juice with a concentration of ethyl 2, 4- decadienoate of $0.1 \mathrm{~kg} \mathrm{~m}^{-3}$, data that correspond to an industrial process in operation. In the desorption step, ethanol was used as stripping agent. Experimental and simulated data confirmed the possibility of increasing the aroma concentration in the stripping phase up to 20 times the feed value.
\end{abstract}

Keywords: Adsorption; Desorption; Aroma compounds; Granular activated carbon; Scalingup. 


\section{INTRODUCTION}

Volatile compounds that constitute the aroma are a complex group of chemical substances that give the characteristic flavour to the fruit juices. The quality of the aroma often determines the acceptability of a processing juice. These organic compounds are present in the juices at low concentrations, usually at ppm levels. The processing juices are usually concentrated, that is, the water is removed in order to improve the microbiological stability and to reduce storage and transport costs (Barrett et al., 2005). The current juice production process involves a series of thermal steps, e.g. evaporation and drying, that can produce aroma changes that usually lower the quality of the product due to looses of the aroma compounds (Bomben et al., 1973). In order to carry out the aroma recovery, the condensed vapor fraction from the first evaporation step is led to a rectification column, where the aroma compounds are concentrated to accomplish appropriate market specifications. In Figure 1 the flow diagram of the conventional process of concentrated pear juice is shown together with the proposed alternative.

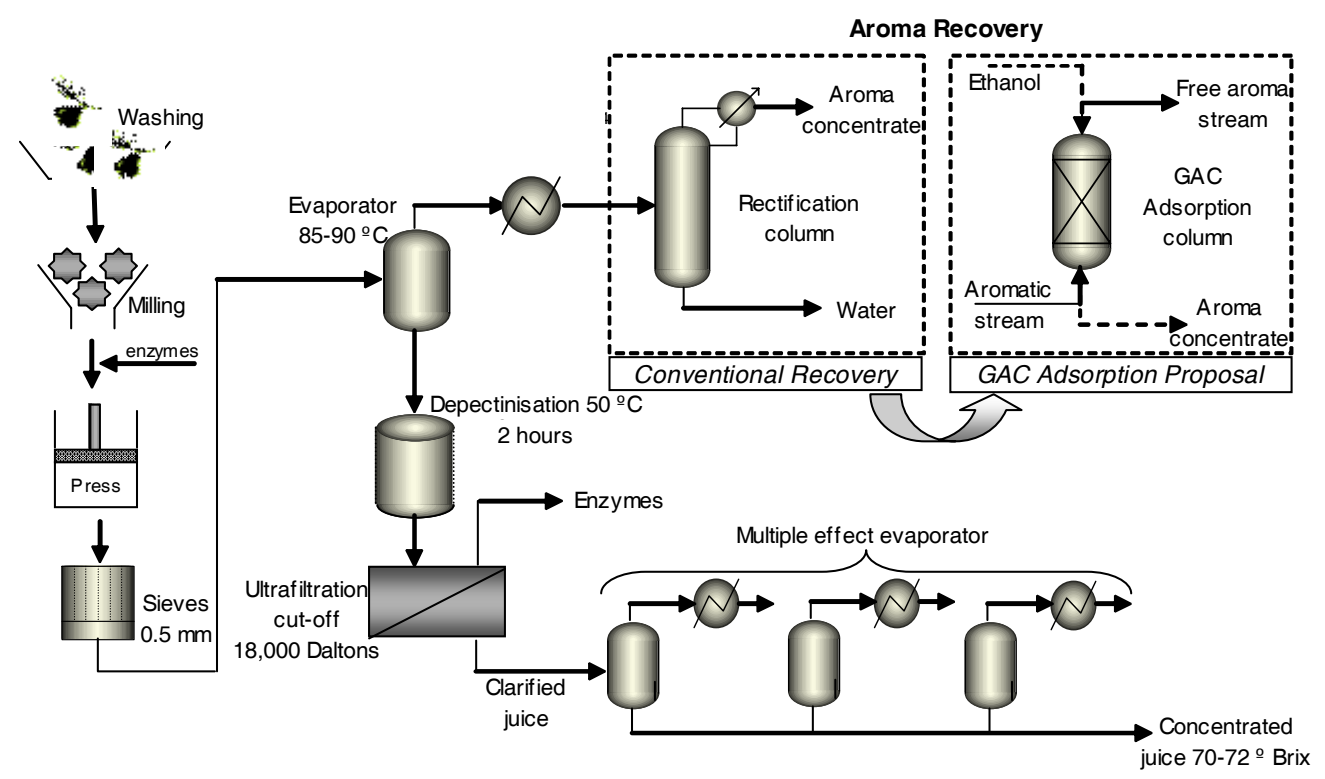

Figure 1. Conventional process for the production of concentrated pear juice and a GAC adsorption column alternative.

Rectification entails high energy costs, and other technologies, like adsorption onto activated carbon (Edris et al., 2003; Lucas et al., 2004), have been proposed as alternative for the aroma recovery to those thermal treatments in order to improve the quality of the aroma obtained from the natural fruit source and also to decrease the energy costs associated to thermal processes. In the work published by Karlsson and Trägårdh (1997), activated carbons were recognised as the best adsorbent materials, adsorbing more than $86 \%$ of the aroma. These authors recommend the use of an apolar solvent as elution agent, giving as a resulting product the solvent with high concentration of aroma compounds. Also, Heinz \& Jennings (1966) collected the volatile compounds of Barlett pears from the processing line of the pear puree by employing charcoal adsorption followed by ether elution.

The volatile organic compounds giving the flavour properties characteristic of the pears have been characterised in previous works (Riu-Aumatell et al., 2004; Suwanagul and Richardson, 
1998) resulting in the identification of methyl and ethyl esters of 2, 4- decadienoate acids as responsible of the typical flavour impact of pears. Ethyl 2, 4- decadienoate is a valuable compound for the juice processing industry and also for food and cosmetic industry in general. For that reason, after separation of the aroma from the aqueous solution, it is necessary its recovery and concentration into a non-aqueous phase, obtaining the extract or essence of the aroma. Several techniques of desorption are available in the literature, such as the classical thermal regeneration desorption (Chu et al., 2004), high pressure and temperature regeneration (Rivera-Utrilla et al., 2003; Salvador and Sánchez, 1999), by means of a stripping phase (Gupta et al., 2005), and more recent techniques such as ultrasonic desorption (Juang et al., 2005).

Based on previous studies (Diban et al., 2006a) adsorption was selected as the technological alternative for substitution of the actual rectification step in the recovery of the main pear aroma compound. Thermal desorption using ethanol as stripping phase led to good results that together with the simplicity of the experimental system facilitated the recovery of the aroma.

In this work, the mathematical model developed previously was employed to define a large scale process of aroma recovery based on GAC adsorption /desorption technology.

\section{MATHEMATICAL MODEL DEVELOPMENT}

In previous works (Diban et al., 2006a, b) adsorption experiments in a laboratory scale GAC fixed-bed were made working in a once-through mode. Synthetic solutions of ethyl 2, 4decadienoate (Sigma-Aldrich) were prepared in 30/70 v/v \% ethanol absolute (Panreac Química)/Milli-Q water (Millipore Corporation). The experiments were carried out at several initial concentrations of ethyl 2, 4- decadienoate and at adsorption temperatures ranging between 283-310 K. Desorption lab-scale experiments were performed in semi-continuous mode using ethanol as stripping phase at constant temperature of $322 \mathrm{~K}$.

With the obtained experimental results the equilibrium isotherms were defined. Freundlich isotherm fitted better the experimental data but thermodynamic parameters could be better calculated with Langmuir isotherm by means of the van't Hoff equation. A kinetic mathematical model, including liquid-film mass transport resistance and intraparticle diffusion, implemented in the software tool Aspen Custom Modeler was developed. The effective pore diffusivity, $D_{p}^{*}$, was estimated with this program using the data obtained in a wide range of temperatures. The results of equilibrium, thermodynamic and kinetic parameters are summarized in Table1.

The kinetic model was generalized within the range of temperatures studied by including temperature dependent correlations to the set of equations previously developed (Diban et al., 2006a). 
Table 1. Summary of the equilibrium, thermodynamic and kinetic parameters obtained in previous works (Diban et al., 2006b).

\begin{tabular}{|c|c|c|c|c|c|c|c|}
\hline \multirow{2}{*}{$\begin{array}{l}T \\
\text { (K) }\end{array}$} & \multicolumn{3}{|c|}{ Langmuir parameters } & \multicolumn{3}{|c|}{ Thermodynamic parameters } & \multirow{2}{*}{$\begin{array}{l}\text { Kinetic parameters } \\
D_{p}{ }^{*}\left(\boldsymbol{m}^{2} \boldsymbol{s}^{-1}\right) \\
\text { (estimated) }\end{array}$} \\
\hline & 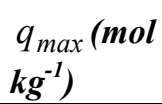 & $\begin{array}{l}K_{L}\left(\boldsymbol{m}^{3}\right. \\
\left.\boldsymbol{m o l} \boldsymbol{l}^{1}\right)\end{array}$ & $r^{2}$ & $\begin{array}{l}\Delta G(k J \\
\left.m o I^{1}\right)\end{array}$ & $\begin{array}{l}-\Delta H(k J \\
\left.m o t^{-1}\right)\end{array}$ & $\begin{array}{l}\Delta S(k J \\
\left.\operatorname{mot}^{-1} K^{-1}\right)\end{array}$ & \\
\hline 283 & 3.20 & 9.64 & 0.95 & -5.33 & & \multirow{4}{*}{-(} & $0.47 \times 10^{-9}$ \\
\hline 298 & 3.38 & 5.02 & 0.94 & -4.00 & & & $1.28 \times 10^{-9}$ \\
\hline 310 & 3.69 & 1.98 & 0.96 & -1.75 & & & $3.89 \times 10^{-9}$ \\
\hline 322 & 0.48 & 1.49 & 0.93 & -1.07 & & & $6.14 \times 10^{-9}$ \\
\hline
\end{tabular}

The equations that correlate the physical parameters of the feed solution, that is, the viscosity $\mu$ and the density $\rho_{f}$, with temperature are shown in Eq. (1-2):

$\mu=-0.022 \times T+7.5321 \quad(c P)$

Eq. 1

$\rho_{f}=-1.04 \times T+1247.6\left(\frac{\mathrm{kg}}{\mathrm{m}^{3}}\right)$

Eq. 2

Equilibrium was described by means of Langmuir isotherm (Eq. (3)):

$q_{e}=\frac{q_{\max }^{\text {solv }} \times K_{L} \times C_{e}}{1+K_{L} \times C_{e}}\left(\frac{\mathrm{mol}}{\mathrm{kg}}\right)$

The equilibrium parameter of the Langmuir isotherm, $K_{L}$, follows a dependence with temperature according to the van't Hoff equation, Eq. (4). The values of the thermodynamic parameters, $-\Delta H$ and $\Delta S$, are found in Table1:

$\log _{10}\left(K_{L}\right)=\frac{\Delta S}{R_{g} \times 2.303}-\frac{(-\Delta H)}{R_{g} \times 2.303} \frac{1}{T \times 10^{-3}}\left(\frac{\mathrm{m}^{3}}{\mathrm{~mol}}\right)$

Eq. 4

$q_{\max }^{\text {solv }}$ is the parameter that represents the maximum capacity of adsorption of the solute onto GAC for a given solvent employed. $q_{\max }^{\mathrm{H}_{2} \mathrm{O} / \mathrm{EtOH}}$ is the maximum capacity of adsorption of ethyl 2, 4- decadienoate onto GAC when the solvent is a 70/30 v/v\% water/ethanol solution. The value of $q_{\max }^{\mathrm{H}_{2} \mathrm{O} / \mathrm{EtOH}}$ shown in Eq. (5) is calculated as an average value of the data included in Table 1 for the adsorption experiments at 283, 298 and $310 \mathrm{~K} . q_{\max }^{\mathrm{EtOH}}$ is applied when pure ethanol is used as solvent during desorption runs at $322 \mathrm{~K}$. The value is shown in Eq. (6).

$$
\begin{aligned}
& q_{\max }^{\mathrm{H}_{2} \mathrm{O} / \mathrm{EtOH}}=3.5\left(\frac{\mathrm{mol}}{\mathrm{kg}}\right) \\
& q_{\max }^{\mathrm{EtOH}}=0.48\left(\frac{\mathrm{mol}}{\mathrm{kg}}\right)
\end{aligned}
$$


The kinetic parameters of the model such as the molecular diffusivity, $D_{m}$, and the effective pore diffusivity, $D_{p}^{*}$, were correlated with temperature by means of Eq. (7) and (8):

$$
\begin{aligned}
& D_{m}=2.06 \times 10^{-12} \times \frac{T}{\mu}\left(\frac{m^{2}}{s}\right) \\
& \log _{10}\left(D_{p}^{*}\right)=-2942 \times \frac{1}{T}+1.04\left(\frac{m^{2}}{s}\right)
\end{aligned}
$$

The resulting generalized model was employed to simulate the adsorption/desorption curves at a large scale GAC fixed-bed.

\section{PROCESS SCALE-UP}

Data of an industrial plant processing the pear juice were provided by the company Nufri (Lleida, Spain).

In the industrial process (Figure 1), 1200 Tons of pears are processed in a cycle of 24 hours, to generate a $7 \mathrm{~m}^{3} \mathrm{~h}^{-1}$ stream of aromatic fraction leaving the first evaporator, with an average ethyl 2, 4-decadienoate concentration of $0.1 \mathrm{~kg} \mathrm{~m}^{-3}$.

Samples of 150 -fold of the aroma concentrated coming from the conventional rectification column were provided by Nufri. A posterior concentration of this aroma to reach 3000 -folds was made also by means of rectification. These samples were analysed using GC (Shimadzu, model GC-2010) with a flame ionization detector (FID) equipped with a DB-Wax chromatographic column (10 $\mathrm{m} \times 0.1 \mathrm{~mm}$ I.D.). The temperature was programmed from 60 to $230{ }^{\circ} \mathrm{C}$ at a rate of $60{ }^{\circ} \mathrm{C} \mathrm{min}^{-1}$. The injector and detector temperatures were set to 250 and 300 ${ }^{\circ} \mathrm{C}$, respectively. The carrier gas was helium that flowed at a linear velocity of $50 \mathrm{~cm} \mathrm{~s}^{-1}$ and a split ratio 1:10. In the sample of 150 -folds, a concentration of $14.6 \mathrm{mg} \mathrm{l}^{-1}$ of ethyl 2, 4decadienoate was determined. In the sample of 3000-folds, no presence of ethyl 2, 4decadienoate was detected. Therefore, it was concluded that during the conventional aroma concentration step the main pear aroma compound is lost, thus it is justified the search of alternative technologies that allow aroma recovery.

A first determination of the size of the industrial granular activated carbon bed was made by means of the Eq. (9) (Cooney, 1999):

$$
L=\frac{(H) t_{\text {service }}}{(1-\varepsilon)\left(q_{0} / C_{0}\right)}
$$

Eq. 9

This equation is developed from the mass balance for equilibrium non-dispersive conditions and for a convex isotherm. This expression allows to calculate the bed length, $L$, as a function of the desired service time, $t_{\text {service}}$, the hydraulic loading, $H$, the solid-phase volume fraction, $(1-\varepsilon)$, and the ratio $\left(q_{0} / C_{0}\right)$, that is, the adsorbed ethyl 2 , 4- decadienoate concentration in the solid-phase, that is in equilibrium with the feed liquid-phase concentration, to the feed concentration.

The hydraulic loading is defined by the expression:

$$
H=\frac{Q}{S}
$$


being $Q$ the flow rate and $S$ the area of the cross section of the bed.

Therefore, rearranging Eq. (9), Eq. (11) is obtained, that together with Eq. (12) allow calculation of bed dimensions:

$$
\begin{aligned}
& V=\frac{(Q) t_{\text {service }}}{(1-\varepsilon)\left(q_{0} / C_{0}\right)} \\
& V=\pi R^{2} L
\end{aligned}
$$

being $V$ the bed volume and $R$ the bed radius.

Hence, the volume of the fixed-bed required for the treatment of the aromatic stream was calculated. Pilot-scale adsorber beds have lengths typically ranging between 6 to 20 times the bed diameters (Cooney, 1999). A length 8 times the diameter was selected due to the geometrical similarity to the laboratory set-up.

The first approach to the column size was calculated with this set of equations for a $t_{\text {service }}$ of 24 hours obtaining a bed of $1.47 \mathrm{~m}$ length and $0.18 \mathrm{~m}$ of diameter. The size of this column was calculated in order to work for 24 hours to complete saturation. The breakthrough curve is shown in Figure 2. Nevertheless, only $65.7 \%$ of the aromatic fraction of the feed is retained onto the GAC column working with this column. 5\% of the feed concentration was established as the breakthrough concentration; when this value was reached the feed flow through the column was stopped. Hence, a second approach was made allowing the column to work for 48 hours. The column size calculated was $1.85 \mathrm{~m}$ length and $0.22 \mathrm{~m}$ of diameter accomplishing the restriction imposed in the outlet stream and retaining $99.7 \%$ of the inlet aromatic feed.

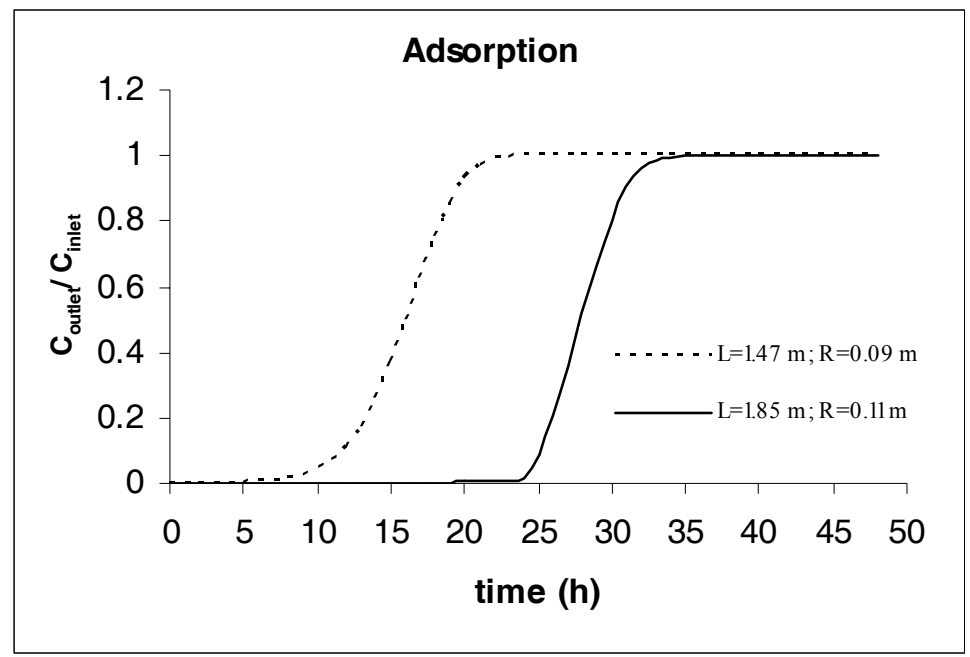

Figure 2. Adsorption breakthrough curves in the large-scale columns.

Desorption cycles were performed working continuously at $50{ }^{\circ} \mathrm{C}$ and with a flow rate of ethanol of $4.8 \mathrm{~m}^{3} \mathrm{~h}^{-1}$. Figure 3 shows desorption curves simulated for the column of $1.85 \mathrm{~m}$ length and $0.22 \mathrm{~m}$ diameter. 


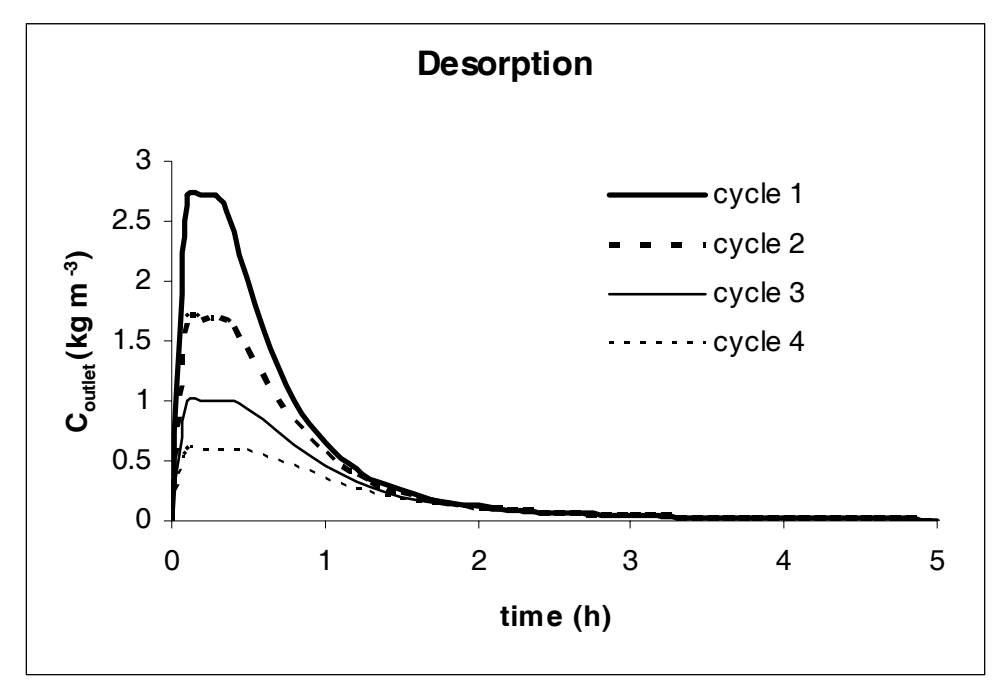

Figure 3. Desorption cycles. Column length 1.85 m.

In Figure 3 it is observed that the maximum concentration of the aroma compound is obtained in the first desorption cycle. The cycle 1 was cut at 0.4 hours, moment where a maximum concentration of the aroma compound had been obtained. A solution with a volume of 1.92 $\mathrm{m}^{3}$ and a concentration of $2.33 \mathrm{~kg} \mathrm{~m}^{-3}$ was obtained, 23 times more concentrated than the feed stream entering the column. $26.7 \%$ of the aroma compound adsorbed was desorbed in this cycle. Therefore, consecutive cycles were performed to recover the maximum amount of ethyl 2,4 - decadienoate. The second cycle was stopped after 0.5 hours obtaining a concentration of $1.48 \mathrm{~kg} \mathrm{~m}^{-3}$, the third was finished at 0.6 hours reaching a concentration of $0.90 \mathrm{~kg} \mathrm{~m}^{-3}$ and the last cycle after 0.6 hours and $0.54 \mathrm{~kg} \mathrm{~m}^{-3}$. In the fourth cycle, $72.52 \%$ of the aroma adsorbed was recovered from the GAC column and the total recovery of the aromatic fraction calculated from the feed stream was $72.29 \%$.

\section{CONCLUSIONS}

The lost of ethyl 2, 4- decadienoate, main pear aroma compound, during the conventional rectification process employed to concentrate the aromatic fraction in the fruit juice production, recommend the search of alternative and efficient technologies. In this work, adsorption onto GAC was the technology selected. Equilibrium parameters and a mathematical kinetic model were previously obtained and generalized with temperature and they were employed to scale-up the process in order to recover and concentrate the main pear aroma compound up to $2.33 \mathrm{~kg} \mathrm{~m}^{-3}$. The column size needed to treat and substitute the rectification unit was $1.85 \mathrm{~m}$ long and $0.22 \mathrm{~m}$ of diameter. The outlet aroma concentration was always under the target value of $5 \%$ the feed concentration and the GAC bed retained $99.7 \%$ of the aroma coming from the feed stream. Data confirm the possibility of obtaining concentrated aroma twenty times higher than the concentration in the aromatic fraction leaving the first evaporator of the industrial plant.

\section{ACKNOWLEDGEMENTS}

Financial support of the Spanish Ministry of Education and Science (MEC) under projects PPQ2003-00934 and CTQ2005-02583 and F.P.I. grant are gratefully acknowledge. Nufri kindly provided the information about the process conditions. 


\section{LITERATURE CITED}

Barrett, D.M.; Somogyi, L.; Ramaswamy, H., 2005, Processing Fruits. CRC Press LLC: Boca Raton.

Bomben, J.L., Briun, S., Thijssen, H.A.C., Merson, R.L., 1973, Aroma recovery and retention in concentration and drying foods, in: Advances in Food Research, Academic Press, London.

Chu, B.S., Baharin, B.S., Che Man, Y.B., Quek, S.Y., 2004, Journal of Food Engineering, 64, 1.

Cooney, D.O., 1999, Adsorption design for wastewater treatment, Lewis Publishers: Boca Raton.

Diban, N., Ruiz, G., Urtiaga, A., Ortiz, I., 2006, Journal of Food Engineering, article in press, available on-line http://www.sciencedirect.com.

Diban, N., Ruiz, G., Urtiaga, A., Ortiz, I., 2006, Journal of Food Engineering, sent.

Edris, A.E., Girgis, B.S., Fadel, H.H.M., 2003, Food Chemistry, 82, 195.

Heinz, D.E., Jennings, W.G., 1966 Journal of Food Science, 31, 69.

Juang, R., Lin, S., Cheng, C., 2005, Ultrasonics Sonochemistry, article in press.

Karlsson, H.O.E., Trägårdh, G., 1997, Journal of Food Engineering, 34, 159.

Lucas, S., Cocero, M.J., Zetzl, C., Brunner, G., 2004, Fluid Phase Equilibria, 219, 171.

Riu-Aumatell, M., Castellari, M., López-Tamames, E., Galassi, S., Buxaderas, S., 2004, Food Chemistry, 87, 627.

Rivera-Utrilla, J., Ferro-García, M.A., Bautista- Toledo, I., Sánchez-Jiménez, C., Salvador, F., Merchán, M.D., 2003, Water Research, 37, 1905.

Salvador, F., Sánchez Jiménez, C., 1999, Carbon, 37, 577.

Suwanawul, A., Richardson, D.G., 1998, Proceedings of the VIIth International Symposium on Pear Growing, Talca, Chile. 